\title{
Neuropeptide S differently modulates alcohol-related behaviors in alcohol-preferring and non-preferring rats
}

\author{
Nazzareno Cannella ${ }^{1}$ - Marsida Kallupi ${ }^{1} \cdot$ Hong $\mathrm{Wu} \mathrm{Li}^{1} \cdot$ Serena Stopponi ${ }^{1}$. \\ Carlo Cifani $^{1} \cdot$ Roberto Ciccocioppo $^{1} \cdot$ Massimo Ubaldi $^{1}$
}

Received: 27 January 2016 / Accepted: 17 May 2016

(C) Springer-Verlag Berlin Heidelberg 2016

\begin{abstract}
Rationale Neuropeptide S (NPS) displays unique pharmacological properties and induces both anxiolytic and pro-stress/ arousal activities. Previous studies performed using Wistar rats demonstrated that NPS facilitated alcohol and cocaine seeking but did not affect alcohol or cocaine consumption. Objectives Here, we investigated the effects of NPS in Marchigian Sardinian alcohol-preferring (msP) rats, a rat strain characterized by excessive alcohol consumption comorbid with heightened anxiety and depressive-like phenotypes. Specifically, we evaluated the effect of NPS on operant alcohol self-administration by msP rats compared to Wistar rats. The effect of NPS on cue-induced reinstatement of alcohol seeking in msP rats was also evaluated. Finally, using the open field test (OFT) and the elevated plus maze (EPM), we evaluated the effects of NPS on locomotor activity and anxiety. Results NPS reduced alcohol self-administration but did not affect cue-induced reinstatement in the msP rat. In addition, NPS induced reinstatement of extinguished alcohol seeking in Wistar rats without affecting alcohol intake. In the EPM task, NPS, in accordance with its anxiolytic activity, increased the time spent in the open arm of the arena by msP rats, although this effect was not observed in Wistar rats.

Conclusions These data suggest that the effect of NPS is strongly influenced by the genetic background of the animal. In Wistar rats, NPS acts as a pro-arousal agent to promote the reinstatement of alcohol seeking. However, when alcohol drinking is motivated by or associated with a state of

Massimo Ubaldi

massimo.ubaldi@unicam.it

1 School of Pharmacy, Pharmacology Unit, University of Camerino, Building of Experimental Medicine, Via Madonna delle Carceri 9, Camerino, MC 62032, Italy
\end{abstract}

pathological anxiety, NPS attenuates alcohol consumption and seeking due to its anxiolytic activity.

Keywords NPSR $\cdot$ Addiction $\cdot$ Relapse $\cdot$ Ethanol $\cdot$ Abuse . CNS

\section{Introduction}

Neuropeptide S (NPS) is a 20-amino-acid neuropeptide, and its transcript is largely expressed in three brainstem areas: the lateral parabrachial nucleus, the principal sensory trigeminal nucleus, and the area surrounding the locus coeruleus (Liu et al. 2011; Xu et al. 2007; Xu et al. 2004). Conversely, its cognate $\mathrm{Gq} / \mathrm{s}$ G protein-coupled receptor (NPSR) is widely expressed throughout the central nervous system (Leonard and Ring 2011; Xu et al. 2007; Xu et al. 2004). In agreement with the wide brain distribution of NPSR, the NPS system is involved in the modulation of a variety of functions, such as locomotion, anxiety, stress, fear conditioning, memory, and food intake (Pape et al. 2010; Reinscheid 2008). In addition, several preclinical studies strongly indicate that the NPS system is involved in drug addiction and alcohol dependence (Cannella et al. 2012; Ghazal et al. 2013; Kallupi et al. 2010; Paneda et al. 2009; Ubaldi et al. 2016). This role of NPS was recently confirmed by a human study that associated increased intrinsic activity of NPSR with more severe alcohol use disorder and increased alcohol consumption (Laas et al. 2015).

We previously demonstrated that the injection of NPS into Wistar rats via the intracerebroventricular (ICV) or intralateral hypothalamus $(\mathrm{LH})$ route potentiates cue-induced reinstatement of alcohol seeking without altering alcohol selfadministration (Cannella et al. 2009). Subsequently, we reported a similar pattern of NPS effects on cocaine seeking (Kallupi et al. 2010; Kallupi et al. 2013). Our findings agreed 
with those of another study (Badia-Elder et al. 2008) reporting that ICV NPS administration does not affect alcohol consumption by non-preferring (NP) rats. However, these authors also reported that NPS, at least under conditions of home cage drinking, can decrease alcohol intake by alcohol-preferring (P) rats. In addition, NPS exerted an anxiolytic-like effect on a $P$ strain but not on an NP strain (Badia-Elder et al. 2008). P rats are characterized by an innate anxious phenotype, and it has been hypothesized that their excessive alcohol drinking is driven in part by the ability of alcohol to relieve them from this negative affective state (Stewart et al. 1993).

The anxiolytic-like properties of NPS have been documented in a number of studies performed under various experimental conditions (Jungling et al. 2008; Leonard et al. 2008; Lukas and Neumann 2012; Rizzi et al. 2008; Vitale et al. 2008; Xu et al. 2004). Hence, in P rats, NPS likely decreases alcohol consumption not because it acts by modulating the rewarding properties of ethanol but rather because of its anxiolytic-like properties. On the other hand, in addition to its anxiolytic activity, NPS has pro-stress and pro-arousal properties (Okamura and Reinscheid 2007). This aspect of NPS pharmacology is likely related to its ability to facilitate relapse behavior. Indeed, we demonstrated that NPS exacerbates the reinstatement of alcohol and cocaine seeking via the stimulation of hypothalamic hypocretin-1/orexin-A signaling (Cannella et al. 2009; Kallupi et al. 2010; Ubaldi et al. 2016). Moreover, Paneda and coworkers reported that NPS is unable to induce reinstatement of extinguished cocaine seeking in mice lacking the receptor corticotropin-releasing factor 1 (CRF1); this finding provides additional support for a role of pro-arousal mechanisms in sustaining this effect of NPS (Paneda et al. 2009).

Taken together, this evidence suggests that NPS might have a dual and, to some extent, paradoxical effect on alcohol drinking and seeking depending on the genetic background and the emotional state of the animal. In the present study, we further evaluated this hypothesis by examining the effects of NPS in Wistar rats compared to Marchigian Sardinian alcohol-preferring (msP) rats. MsP rats, similar to the $\mathrm{P}$ strain, exhibit a genetic predisposition toward high levels of alcohol consumption; msP rats are highly vulnerable to the reinstatement of alcohol seeking, are hypersensitive in response to stress, and show an anxious- and depression-like phenotype (Ciccocioppo et al. 2006; Ciccocioppo et al. 1999; Gozzi et al. 2013; Hansson et al. 2007; Hansson et al. 2006). In previous studies, we proposed that msP rats consume alcohol for self-medication purposes to alleviate their innate negative affective state (Ciccocioppo et al. 2006; Hansson et al. 2006). Hence, considering that NPS exerts anxiolytic-like effects, we hypothesized that NPS would reduce alcohol consumption and seeking in these animals while exerting no effect on the opposite effect in Wistar rats.

\section{Materials and methods}

\section{Animals}

Male Wistar rats (Charles River, Calco, Italy) and msP rats bred at the School of Pharmacy, University of Camerino, weighing 175-225 $\mathrm{g}$ at the beginning of the study were used. Pairs of rats were housed in a room with an artificial $12 \mathrm{~h} / 12 \mathrm{~h}$ light/dark cycle (lights off at 8:00 a.m.) at constant temperature $\left(20-22^{\circ} \mathrm{C}\right)$ and humidity $(45-55 \%)$. All training and experimental sessions were conducted once a day during the nocturnal phase of the light/dark cycle. All procedures adhered to the European Community Council Directive and the National Institutes of Health Guidelines for the Care and Use of Laboratory Animals and were approved by the Ethics Committee of the University of Camerino (Protocol no. 1/ 2012).

\section{Intracranial surgery}

Animals were anesthetized via intramuscular injection of $100-150 \mu \mathrm{l}$ of a solution containing tiletamine hydrochloride $(58.17 \mathrm{mg} / \mathrm{ml})$ and zolazepam hydrochloride $(7.5 \mathrm{mg} / \mathrm{ml})$. For drug injections, guide cannulae $(0.65-\mathrm{mm}$ outside diameter) were stereotaxically implanted and cemented to the skull. For ICV cannula placement, the coordinates in millimeters with reference to bregma were as follows: anteroposterior (AP) -1.0 , lateral (L) -1.8 , and ventral (V) 2.0. All coordinates were based on the Paxinos and Watson atlases (Paxinos and Watson 1988) and were adjusted for the body weight of the animals. To alleviate postoperative pain, the rats were treated with $2.5 \mathrm{mg} / \mathrm{kg}$ of ketoprofen administered subcutaneously for 2 days. Surgery was followed by a 7-day recovery period, during which the rats were left undisturbed in their home cage.

Before the beginning of the experiments, the animals received ICV injections of saline to habituate them to the drug administration procedure. Appropriate cannula placement was verified before the experiment by performing ICV injection of $100 \mathrm{ng}$ of angiotensin II; only animals showing a clear dipsogenic response (consumption of at least $6 \mathrm{ml}$ of water within $5 \mathrm{~min}$ ) were used for further experimentation.

\section{Drug injection}

NPS, a generous gift of Dr. R. Guerrini, University of Ferrara, Italy, was dissolved in sterile isotonic saline and administered intracerebroventricularly in a volume of $1 \mu \mathrm{l} /$ rat using a stainless-steel injector $2.5 \mathrm{~mm}$ longer than the guide cannula. The injector was connected to a $10-\mu 1$ Hamilton syringe. Once the injector was introduced into the guide cannula, the NPS (or vehicle) solution was infused by gently pushing the syringe piston. After the infusion, the injector was left in place for 
$1 \mathrm{~min}$ before removal to avoid liquid backflow. The NPS or vehicle solution was injected $5 \mathrm{~min}$ before the behavioral tests.

\section{Operant training of alcohol self-administration}

Operant training and testing were performed in selfadministration chambers (Med Associates) equipped with a drinking reservoir (volume capacity $0.30 \mathrm{ml}$ ) and two retractable levers. Auditory and visual stimuli were presented via a speaker and a light located on the front panel, respectively, during the discrimination phase and the reinstatement tests. The rats were trained to self-administer $10 \%$ alcohol $(v / v)$ using a saccharin-fading procedure adapted from Weiss et al. (1990) in 30-min daily sessions on a fixed-ratio of 1 schedule of reinforcement. For the first 5 days of training, presses of the active lever were reinforced by delivery of $0.2 \%(w / v)$ saccharin solution into the drinking receptacle. After the acquisition of the saccharin-reinforced response, alcohol was added to the saccharin solution and the alcohol and saccharin concentrations varied every five training days according the following schedule: saccharin $0.2 \%(w / v)+$ alcohol $5 \%(v / v)$, alcohol $5 \%(v /$ $v)$, saccharin $0.2 \%(w / v)+$ alcohol $8 \%(v / v)$, alcohol $8 \%(v / v)$, and saccharin $0.2 \%(w / v)+$ alcohol $10 \%(v / v)$. The delivery of the solutions was followed by a 5-s time-out period during which the reinforced lever remained inactive.

Each response resulted in the delivery of $0.1 \mathrm{ml}$ of fluid. The number of operant lever presses of both the active and inactive levers and the number of reinforcements received was recorded for each session.

\section{Experiment 1: effect of ICV NPS treatment on alcohol self-administration by $\mathrm{msP}$ and Wistar rats}

The rats ( $n=8 /$ line) were trained to self-administer $10 \%(v / v)$ alcohol using the fading procedure described above. Once saccharin was faded out, each alcohol delivery was paired with the illumination of the chamber's house light, which signaled a 5-s time-out (TO) period. Following the acquisition of a stable baseline of alcohol self-administration, NPS treatment began. In a counterbalanced order, $5 \mathrm{~min}$ before the beginning of the self-administration session, the rats received an ICV injection of NPS $(0.1,0.5,1.0$, or $2.0 \mathrm{nmol} / \mathrm{rat})$ or its vehicle. Drug treatment was performed every fourth day. On the first day after each drug injection, the rats remained in their home cages, whereas on the 2nd and 3rd day after each drug injection, baseline alcohol self-administration was reestablished.

\section{Experiment 2: effect of ICV NPS treatment on open field test performance by msP and Wistar rats}

For the open field test (OFT), the rats were placed in a Plexiglas arena $(43 \times 43 \mathrm{~cm})$ that recorded subject location using 16 evenly spaced infrared (I/R) transmitters and receivers positioned around the periphery of the chamber (Med Associates). The OFT was performed in a soundattenuated room illuminated by a dim red light $(\sim 30 \mathrm{~lx})$.

The rats received an ICV injection of NPS $(0.25$ and $1.0 \mathrm{nmol} / \mathrm{rat}$ ) $5 \mathrm{~min}$ before the beginning of the test.

Wistar ( $n=24 ; 8 /$ group) and msP rats ( $n=25 ; 8-9 /$ group) were placed in the center $(28 \times 28 \mathrm{~cm})$ of the open field arena, and their activity was recorded for $15 \mathrm{~min}$. Movement time, total distance traveled, time spent in the center, and distance traveled in the center were analyzed using the Activity Monitor software (Med Associates).

\section{Experiment 3: effect of ICV NPS treatment on elevated plus maze task performance by msP and Wistar rats}

The elevated plus maze (EPM) task was performed in a soundattenuated room illuminated by a dim red light $(\sim 30 \mathrm{~lx})$. The apparatus consisted of four black wooden arms $(50 \mathrm{~cm}$ long $\times 10 \mathrm{~cm}$ wide) arranged such that the respective closed and open arms were opposite to each other. The maze, elevated $50 \mathrm{~cm}$ above the floor, was cleaned with water and dried after each trial. Each 5-min trial began when the animals were individually placed in the center of the maze, facing a closed arm. A rat was considered to be on the central platform when at least two of its paws were on it. An entry was defined as the presence of all four paws in an arm. The percentage of time spent in the open arms [\% OAT $=$ (time in open arms/time in "open arms" + time in "closed" arms) $\times 100]$ and the percentage of open arm entries [\%OAE $=$ (number of open arm entries/total number of "open" or "closed" arm entries) $\times 100$ ] were considered as indexes of anxiety, and the total number of arm entries was used as a measure of spontaneous locomotor activity. The Wistar ( $n=12 /$ group) and msP rats $(n=14 /$ group) received an ICV injection of NPS (1.0 nmol/rat) or its vehicle $5 \mathrm{~min}$ before the beginning of the task.

\section{Experiment 4: effect of ICV NPS treatment on discriminative cue-induced reinstatement of alcohol seeking in Marchigian Sardinian alcohol-preferring rats}

We previously demonstrated that ICV NPS treatment at doses of 2.0 and 4.0 , but not $1.0 \mathrm{nmol} / \mathrm{rat}$, facilitated discriminative cue-induced reinstatement of alcohol seeking in Wistar rats (Cannella et al. 2009). Thus, we repeated this experiment in msP rats $(n=8)$.

The experiment consisted of three phases as follows: discrimination, extinction, and reinstatement.

Discrimination phase Once saccharin was faded out, msP rats were trained to discriminate between $10 \%$ alcohol and water in 30-min daily sessions. Discriminative and discrete stimuli predictive of alcohol $\left(\mathrm{S}^{+}\right)$versus water availability 
$\left(\mathrm{S}^{-}\right)$were presented during the alcohol and water selfadministration sessions, respectively. The discriminative stimulus for alcohol was the odor of orange extract, whereas water availability (i.e., no reward) was signaled by anise extract. The olfactory stimuli were generated by depositing six to eight drops of the respective extract into the bedding in the operant chamber. In addition, each lever press resulting in the delivery of alcohol was followed by a 5-s time-out period (during which the alcohol lever remained inactive) contingently paired with the illumination of the chamber's house light, which served as a discrete stimulus. For the water sessions, the time-out period was signaled by a 5 -s $70-\mathrm{dB}$ tone. The olfactory discriminative stimuli for alcohol or water availability were introduced $1 \mathrm{~min}$ before extension of the levers and remained present throughout the 30-min sessions. The alcohol and water sessions were conducted in a pseudorandom order across distinct training days, with the constraint that all rats received a total of 10 alcohol and 10 water sessions.

Extinction phase After the last conditioning day, rats were subjected to a 30-min daily extinction session. Extinction training was maintained until the responses on the previously active lever dropped below $25 \%$ of the baseline responses under the $\mathrm{S}^{+}$condition (average of the last three sessions) for at least 2 days. During this phase, each trial began with the extension of the levers without presentation of the conditioned stimuli. Responses at the lever activated the delivery mechanism but did not result in the delivery of liquids.

Reinstatement test Reinstatement tests began the day after the last extinction session. The reinstatement test sessions were identical to the discrimination phase sessions, except that alcohol and water were not available. The rats were tested under the $\mathrm{S}^{-}$condition on day 1 and under the $\mathrm{S}^{+}$condition from day 2 onward, with the $\mathrm{S}^{+}$condition trials repeated every third day. The effect of NPS (1.0, 2.0, or $4.0 \mathrm{nmol} / \mathrm{rat})$ or its vehicle on discriminative cue-induced reinstatement of alcohol seeking was evaluated using a Latin square withinsubjects counterbalanced design. NPS was injected to the ICV $5 \mathrm{~min}$ before the test.

\section{Experiment 5: effect of ICV NPS treatment on extinguished alcohol seeking in msP and Wistar rats}

The Wistar $(n=8)$ and $\mathrm{msP}(n=9)$ rats were trained for alcohol self-administration as described for experiment 1 . After the last self-administration session, the rats were subjected to 30-min daily extinction sessions. During this phase, the responses at the active lever illuminated the house light and activated the delivery mechanism but did not result in the delivery of alcohol. Extinction training was maintained until the response rate on the active lever dropped below $25 \%$ of the self-administration baseline rate (average of the last three sessions) for at least 2 days. Once the extinction criteria were achieved, the effect of NPS $(0.1,0.25,0.5,1.0$, or $2.0 \mathrm{nmol} /$ rat) or its vehicle was evaluated under extinction conditions using a Latin square within-subjects counterbalanced design. Between the NPS treatments, trials under the extinction condition were performed to confirm that the rats returned to meet the extinction criteria. Thus, treatments were repeated every third or fourth day depending on the time point of achievement of the extinction baseline.

\section{Statistical analysis}

Behavioral data were analyzed via between- and within-factor ANOVAs as appropriate.

In experiment 1 , the baseline lever press rate at $10 \%$ alcohol self-administration was analyzed via two-way ANOVA, with one factor between subjects (rat strain) and one factor within subjects (reinforced/inactive lever responses). For this analysis, we considered the lever responses averaged across the last 3 days of self-administration. The effect of NPS on alcohol self-administration was also analyzed via three-way ANOVA, with rat strain as a between-subjects factor and NPS dose and reinforced/inactive lever responses as withinsubjects factors. In experiment 2 , the time spent and the distance traveled in the center of the arena and the total distance traveled were analyzed via two-way ANOVA, with the rat strain and NPS dose as between-subject factors. In experiment 3 , the percentage of the time spent in open arms of the EPM and the number of arm entries were analyzed via two-way ANOVA. In experiment 4 , the discrimination baseline was analyzed via two-way ANOVA, with alcohol $\left(\mathrm{S}^{+}\right) /$water $\left(\mathrm{S}^{-}\right)$ conditions and reinforced/inactive lever responses as withinsubject factors. The extinction of lever pressing was analyzed via two-way ANOVA, with active/inactive levers and extinction days as within-subject factors. The reinstatement test results were analyzed via two-way ANOVA, with extinction $/ \mathrm{S}^{+} /$ $\mathrm{S}^{-}$conditions and active/inactive lever as within-subject factors; a response on the last extinction day and $\mathrm{S}^{+}$responses under drug vehicle treatment were used in this analysis. Drug effects on discriminative cue-induced reinstatement of alcohol seeking $\left(\mathrm{S}^{+}\right.$condition) were analyzed via a two-way withinfactors ANOVA (treatment and active/inactive lever). In experiment $5,10 \%$ alcohol self-administration training outcome was analyzed as in experiment 1 . The extinction of lever pressing was analyzed via three-way ANOVA, with rat strain as a between-subject factor and active/inactive levers and extinction days as within-subject factors. The effect of NPS on extinguished alcohol seeking was analyzed via three-way ANOVA, with rat strain as a between-subject factor and active/inactive levers and NPS dose as the within-subject factor. The analyses were followed by the Newman-Keuls post hoc test when appropriate, and statistical significance was set at $p=0.05$. 


\section{Results}

\section{Experiment 1: effect of ICV NPS treatment on alcohol self-administration by $\mathrm{msP}$ and Wistar rats}

One Wistar rat and one msP rat were excluded after the angiotensin II test; thus, this experiment was performed using seven rats per strain. For alcohol self-administration, the mean $\pm \mathrm{SEM}$ alcohol consumption in the last three training days was 1.28 and $0.83 \mathrm{~g} / \mathrm{kg}$ body weight of the msP and Wistar rats, respectively. When lever pressing was evaluated via ANOVA, the statistical analysis revealed an overall effect of rat strain $[\mathrm{F}(1$, $12)=9.07 ; p<0.05]$ and the reinforced/inactive response $\times$ strain interaction $[\mathrm{F}(1,12)=10.69 ; p<0.01]$. These results agree with greater reinforcement of lever responses by $\mathrm{msP}$ rats (Fig. 1). When the effect of NPS on alcohol self-administration was analyzed, we found a dose $\times$ strain interaction $[\mathrm{F}(4,48)=4.16 ; p<0.01]$ and a dose $\times$ strain $\times$ lever interaction $[\mathrm{F}(4,48)=2.66 ; p<0.05]$. The Newman-Keuls post hoc test confirmed that NPS treatment decreased the number of reinforcements received by msP but not Wistar rats (Fig. 1). The number of inactive lever responses was always low and was unaffected by the experimental phase and pharmacological treatment.

\section{Experiment 2: effect of NPS on open field test performance by $\mathrm{msP}$ and Wistar rats}

All rats showed positive results on the angiotensin II test; therefore, all rats were included in the statistical analysis. For the time spent in the center of the arena, ANOVA revealed an overall effect of strain $[\mathrm{F}(1,43)=8.94$, $p<0.01]$, and the overall effect of NPS dose approached significance $[\mathrm{F}(2,43)=2.78, p=0.073]$. The strain $\times$ dose interaction was also significant $[\mathrm{F}(2,43)=3.97, p<0.05]$. The Newman-Keuls post hoc test revealed that the msP rats spent less time in the center of the arena than did the Wistar rats $(p<0.01)$. NPS increased the time spent in the center of the arena by the msP rats, but not the Wistar rats, in a dose-dependent manner $(p<0.05, p<0.01)$ (Fig. 2a). When the distance traveled in the center was analyzed, no significant effect of strain $[\mathrm{F}(1,43)=0,71, p \mathrm{NS}]$ or strain $\times$ dose interaction was observed $[\mathrm{F}(2,43)=0,26, p$ $\mathrm{NS}]$, but there was a significant effect of dose $[\mathrm{F}(2,43)=5$, $25, p<0.01]$. Although a dose-dependent trend of an increased distance traveled in the center was observed in both strains, the Newman-Keuls post hoc test did not find any significant difference between the groups (Fig. 2b). Finally, when the total distance traveled was analyzed, there was a significant effect of strain $[F(1,43)=10,35$, $p<0.01]$ but no significant effect of dose $[\mathrm{F}(2,43)=1,52$,

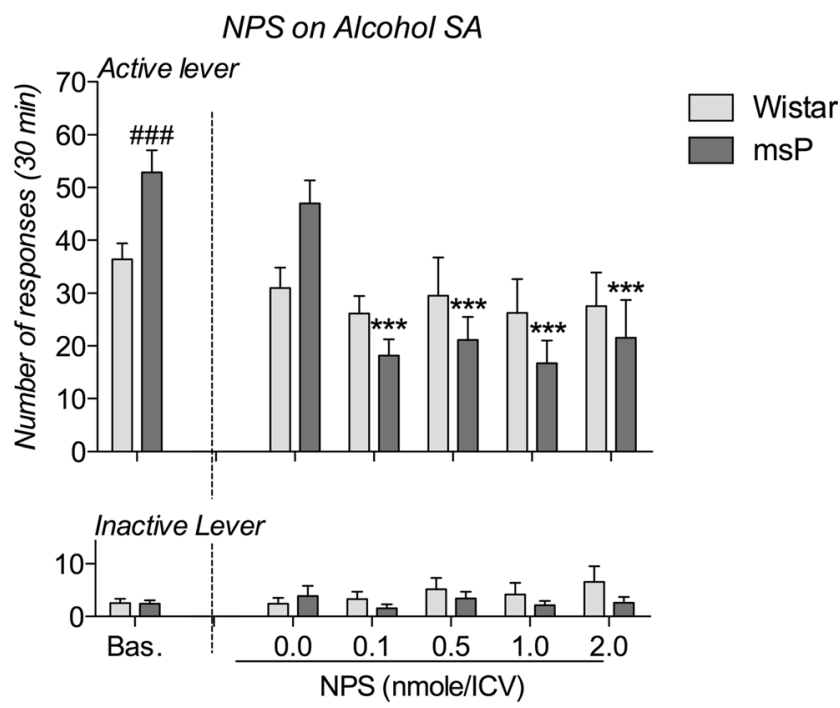

Fig. 1 Effect of intracerebroventricular (ICV) administration of neuropeptide S (NPS) on $10 \%$ alcohol self-administration by msP and Wistar rats. The msP rats presented a higher baseline level of self-administration before testing. Vehicle treatment did not affect alcohol self-administration in either strain. ICV treatment with NPS reduced the number of $10 \%$ alcohol reinforcements received by the msP rats but not the Wistar rats (upper panel), although the inactive lever response rate was not altered by NPS treatment (lower panel). Reinforced and inactive lever presses are reported in the upper and lower panels, respectively. The data are expressed as the means \pm SEM: \#\#\# $<0.001$ vs. Wistar rats under the same conditions; $* * * p<0.001$ vs vehicle treatment in the same strain

$p \mathrm{NS}]$ or strain $\times$ dose interaction $[\mathrm{F}(2,43)=0,42, p \mathrm{NS}]$. The Newman-Keuls post hoc test did not indicate any difference between the two rat strains treated with the same drug doses (Fig. 2c).

\section{Experiment 3: effect of NPS on EPM task performance by $\mathrm{msP}$ and Wistar rats}

The overall ANOVA revealed a significant interstrain difference $[\mathrm{F}(1,48)=6.630 ; p<0.01]$ in the percentage of time spent in the open arms. A significant treatment $\times$ strain interaction $[\mathrm{F}(1,48)=9.184 ; p<0.001]$ was also observed. The post hoc analysis revealed that the msP rats spent less time in the open arms than did the Wistar rats $(p<0.01)$, suggesting a higher level of anxiety among the msP rats (Fig. 3a). After the injection of $1.0 \mathrm{nmol} \mathrm{NPS} / \mathrm{rat}$, the time spent in the open arms by the msP rats increased $(p<0.01)$, whereas no effect was observed in the Wistar rats.

The overall ANOVA also revealed a significant treatment $\times$ strain interaction $[\mathrm{F}(1,48)=7.677 ; p<0.01]$ in the number of open arm entries. The post hoc analysis revealed that the msP rats entered the open arms fewer times $(\underline{p}<0.05)$ than did the Wistar rats. After the injection of $1.0 \mathrm{nmol} \mathrm{NPS} / \mathrm{rat}$, the number of entries into the open arms by the msP rats increased $(p<0.05)$, 

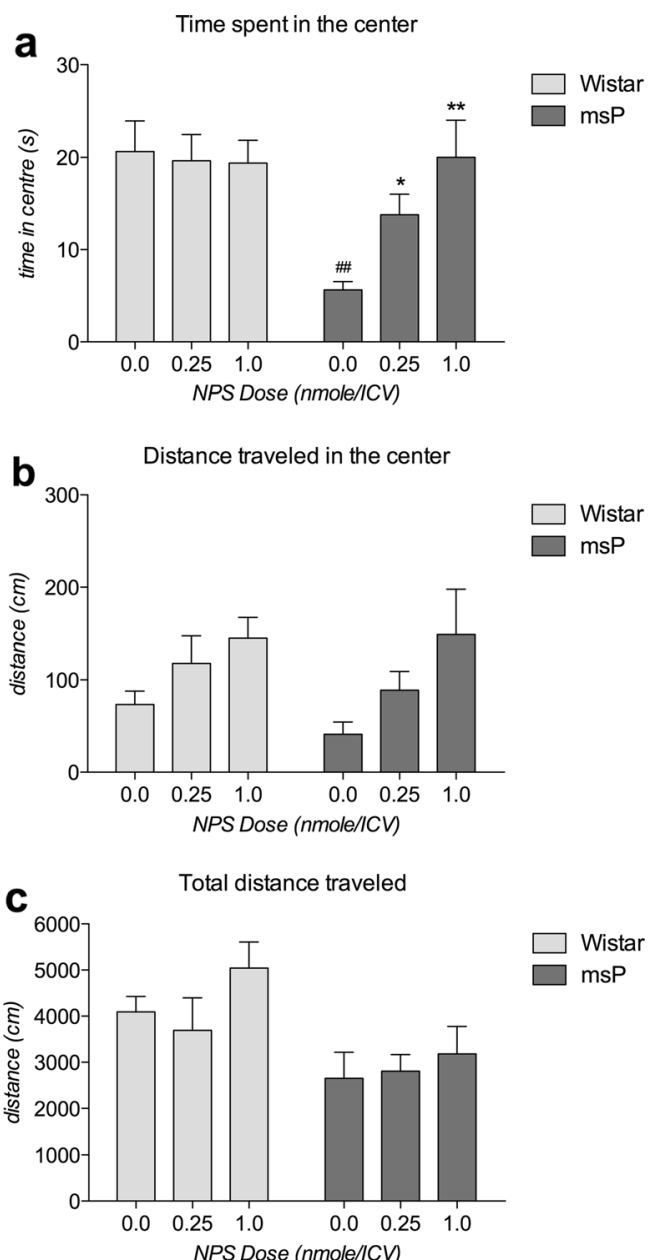

\section{Wistar}

$\mathrm{msP}$
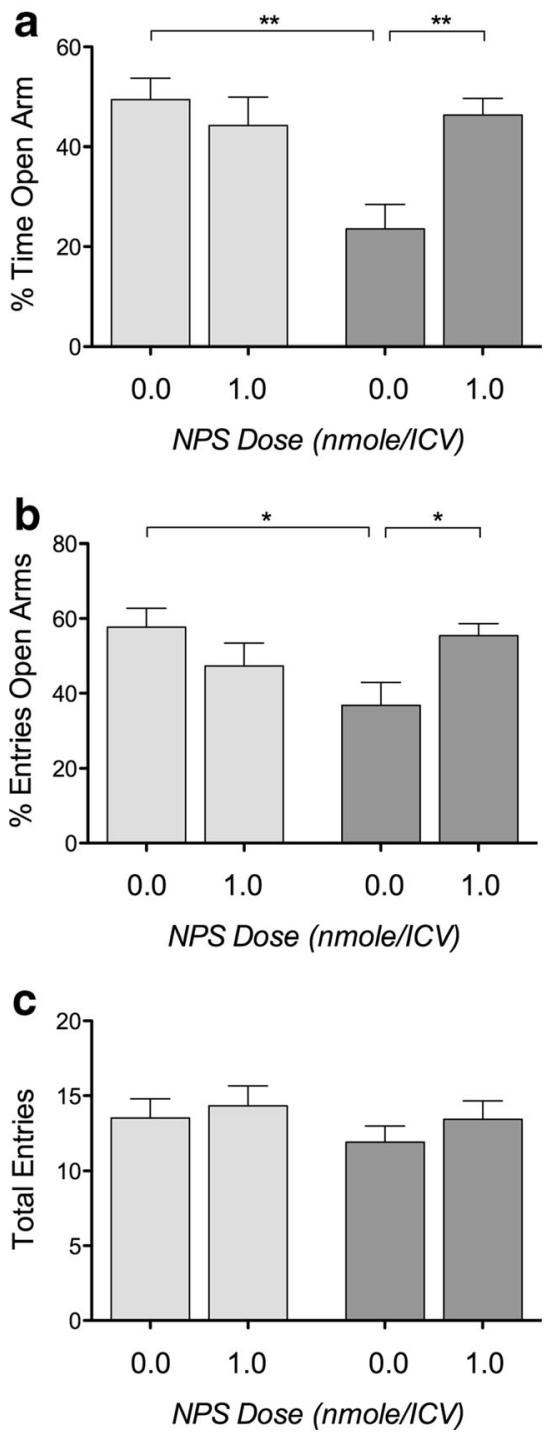

Fig. 3 Effect of ICV NPS (1.0 nmol/rat) injection on elevated plus maze (EPM) task performance. a The percentage of time spent in the open arms was higher in the msP rats than in the Wistar rats. NPS administration reversed anxiety-like behavior in the msP rats, whereas no effects were detected in the Wistar rats. $\mathbf{b}$ The percentage of entries into the open arms was significantly lower in the msP rats than in the Wistar rats. Additionally, in this study, NPS specifically increased the percentage of entries into the open arms in the msP rats. $\mathbf{c}$ The total number of arm entries (open and closed arms) did not differ between the two strains and was not affected by NPS injection. The data are expressed as the means \pm SEM. Difference between the Wistar rats and the msP rats: $\# \# p<0.01$ and $\# p<0.05$; the difference between NPS and vehicle; ${ }^{* *} p<0.01$ and $*_{p}<0.05$

The mean \pm SEM alcohol consumption of the last three discrimination/training alcohol self-administration days corresponded to $1.02 \mathrm{~g} / \mathrm{kg}$. When discrimination was evaluated by ANOVA, the statistical analysis revealed a significant 
effect of condition $[\mathrm{F}(1,7)=93.42 ; p<0.0001]$, levers $[\mathrm{F}(1$, $7)=115.17 ; p<0.0001]$, and condition by lever interaction $[\mathrm{F}(1,7)=51.06 ; p<0.001]$, indicating that the rats successfully discriminated between $\mathrm{S}^{+}$and $\mathrm{S}^{-}$conditions (Fig. 4a). For extinction training, the ANOVA revealed an overall effect of levers $[\mathrm{F}(1,7)=40.44 ; p<0.001]$, day $[\mathrm{F}(9,63)=10.06$; $p<0.000001]$, and day by lever interaction $[\mathrm{F}(9,63)=9.33$; $p<0.000001]$; the response on the active lever progressively decreased until it was no longer different from the inactive lever response (Fig. 4a). During the reinstatement test, exposure to $\mathrm{S}^{+}$, but not $\mathrm{S}^{-}$, reinstated the response on the active lever as demonstrated by an overall effect of levers $[\mathrm{F}(1$, $7)=116.25 ; p<0.0001]$, conditions $[\mathrm{F}(2,14)=24.21$; $p<0.0001]$, and lever by condition interaction $[\mathrm{F}(2$, 14) $=9.40 ; p<0.01]$.

When the effect of NPS on cue-induced reinstatement was analyzed, the ANOVA revealed that both overall effects of treatment $[\mathrm{F}(3,21)=0.58 ; p \mathrm{NS}]$ and lever by treatment interaction $[\mathrm{F}(3,21)=0.89 ; p \mathrm{NS}]$ were not significant (Fig. $4 \mathrm{~b})$. The inactive lever responses were always low and unaffected by experimental phases and pharmacological treatments.

\section{Experiment 5: effect of ICV NPS treatment on extinguished alcohol seeking in $\mathrm{msP}$ and Wistar rats}

One Wistar rat was excluded because it failed to reach the extinction baseline, and one msP rat was excluded after the angiotensin II test; thus, the analysis of this experiment was

SA baseline, Extinction, and S- test

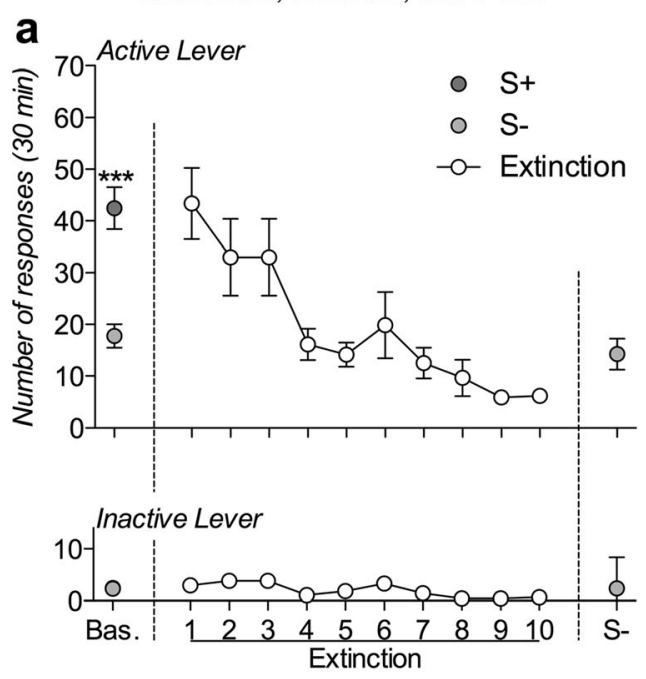

Fig. 4 Effect of ICV administration of NPS on discriminative cueinduced reinstatement of alcohol seeking in $\mathrm{msP}$ rats. a Baseline discrimination between alcohol- $\left(\mathrm{S}^{+}\right)$and water-paired $\left(\mathrm{S}^{-}\right)$environments, as well as extinction training and $\mathrm{S}$ test results. The rats successfully discriminated between $\mathrm{S}^{+}$and $\mathrm{S}^{-}$conditions, exhibiting higher alcohol reinforcement than water reinforcement during discrimination training (Bas.). During extinction, active lever pressing progressively decreased, and lever performed in seven Wistar and eight msP rats. For alcohol self-administration, the mean \pm SEM alcohol consumption in the last three training days was 1.07 and $0.67 \mathrm{~g} / \mathrm{kg}$ in $\mathrm{msP}$ and Wistar rats, respectively. When lever pressing was evaluated via ANOVA, the statistical analysis revealed a significant overall effect of strain $[\mathrm{F}(1$, $13)=5.41 ; p<0.05]$ and lever $\times$ strain interaction $[\mathrm{F}(1$, $13)=8.11 ; p<0.05]$, and these results were consistent with a higher rate of reinforced lever responses by the $\mathrm{msP}$ rats during baseline self-administration (Fig. 5a). For extinction training, the ANOVA revealed a significant lever $\times$ day $\times$ group interaction $[F(11,143)=2.60$; $p<0.01]$. As expected, at the beginning of extinction training, the msP rats performed a greater number of active lever presses than did the Wistar rats, confirming a higher motivation for alcohol seeking among the msP rats. At the end of the extinction phase, no differences in lever pressing were observed between the msP and Wistar rats (Fig. 5a). When the effect of NPS on extinguished alcohol seeking was tested, the ANOVA revealed the overall effects of strain $[\mathrm{F}(1,13)=19.12 ; p<0.001]$, dose $[\mathrm{F}(5$, $65)=10.34 ; p<0.00001]$, and lever $[\mathrm{F}(1,13)=64.19$; $p<0.00001]$ and a significant lever $\times$ dose $\times$ strain interaction $[\mathrm{F}(5,65)=8.69 ; p<0.00001]$. The Newman-Keuls post hoc test confirmed that the msP and Wistar rats exhibited similar rates of lever responses under the vehicle condition and that NPS reinstated the active lever responses in the Wistar but not in the msP rats (Fig. 5b).

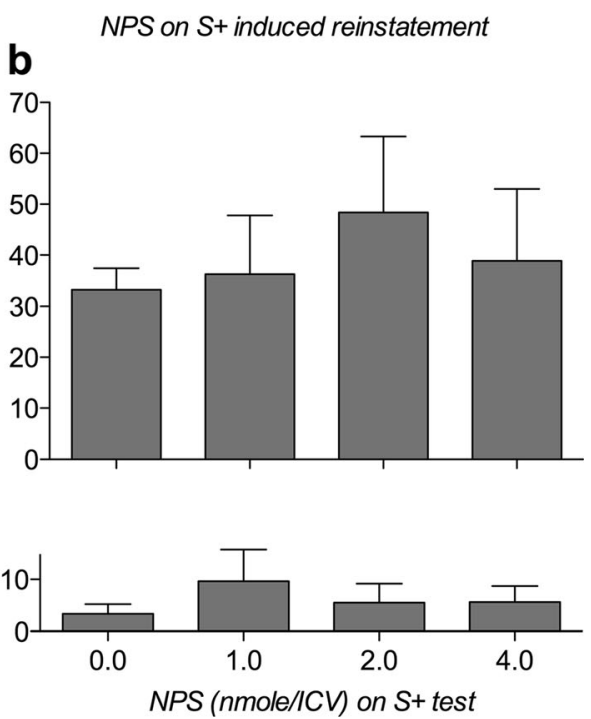

pressing was sustained at the extinction level upon exposure to the $\mathrm{S}^{-}$ stimuli. b Effect of NPS on the $\mathrm{S}^{+}$stimulus-induced reinstatement of alcohol seeking. Exposure to alcohol-predictive discriminative stimuli $\left(\mathrm{S}^{+}\right)$reinstated active lever pressing and this effect was not altered by ICV administration of NPS. Reinforced and inactive lever presses are presented in the upper and lower panels, respectively. The data are expressed as the means \pm SEM: $* * * p<0.001, \mathrm{~S}^{+}$vs $\mathrm{S}^{-}$ 


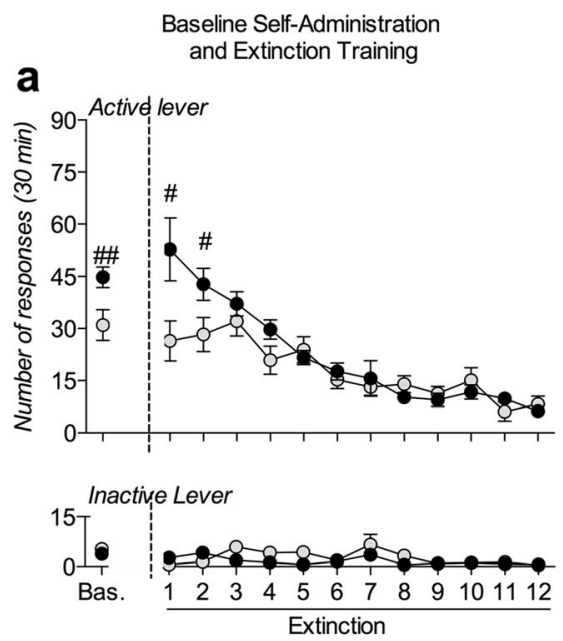

Fig. 5 Effect of ICV administration of NPS on extinguished alcohol seeking in the msP and Wistar rats. a Baseline self-administration and extinction training. The msP rats exhibited a higher baseline level of alcohol self-administration than the Wistar rats. During the first 2 days of extinction training, the msP rats performed a greater number of active lever presses than the Wistar rats, but both groups reached a similar level

\section{Discussion}

The results showed that NPS exerts distinct effects on alcohol drinking and seeking depending on the genetic background. In outbred Wistar rats, ICV injection of NPS did not modify alcohol self-administration but elicited a marked increase in lever pressing under the extinction condition suggestive of a priming-like effect, leading to reinstatement of alcohol seeking. This evidence expands our previous findings that central NPS injection enhanced alcohol seeking and relapse elicited by the presentation of discriminative cues signaling drug availability (Cannella et al. 2009). When we administered NPS to genetically selected msP rats, we recorded a completely different response to NPS: operant alcohol selfadministration was reduced and lever pressing under extinction conditions or following cue presentation were not increased. These effects of NPS on lever pressing cannot be attributed to changes in locomotor performance because the total distance traveled in the OFT was not modified by NPS at the doses used here. Interestingly, however, when we measured the distance traveled and the time spent in the center of the arena, we observed two important phenomena: (1) compared to the Wistar rats, the msP rats spent less time and showed lower locomotor activity in the center of the arena, possibly reflecting higher anxiety and (2) the NPS administration ameliorated this difference by enhancing the center arena performances of $\mathrm{msP}$ rats, indicating a rat strain-specific effect of NPS.

In addition to having an innate high preference for alcohol and for drinking excessive amounts of alcohol [6-8 $\mathrm{g} / \mathrm{kg}$ body weight per day (Ciccocioppo et al. 2006)], the msP rats are highly sensitive to stress and stress-induced alcohol seeking
NPS on extinguished alcohol seeking
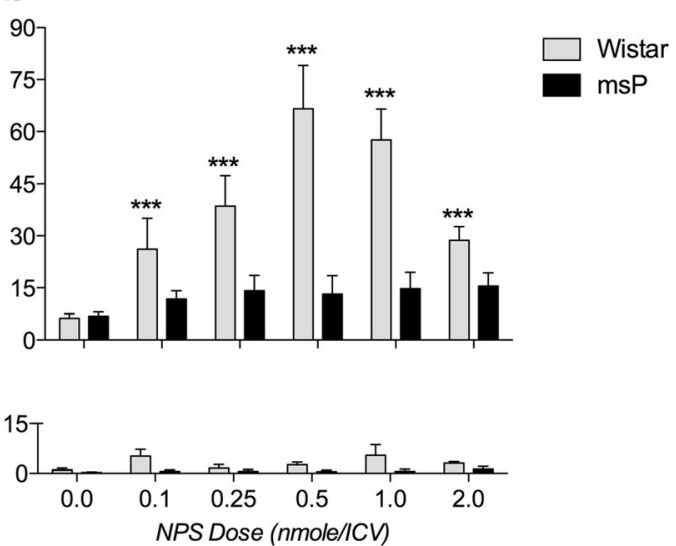

of extinction after 12 days. b Effect of NPS on extinguished alcohol seeking. ICV treatment with NPS reinstated the response to the active lever in the Wistar rats but not the msP rats. No effects on presses of the inactive control lever were detected. The data are expressed as the means \pm SEM. Difference between msP and Wistar rats: $\# p<0.05$, \#\# $p<0.01$; difference between NPS and vehicle: $* * * p<0.001$

(Ciccocioppo 2013; Ciccocioppo et al. 2006), show depressive-like traits (Ciccocioppo et al. 1999; Gozzi et al. 2013), and demonstrate an anxious-like phenotype that recovers following alcohol drinking (Ayanwuyi et al. 2013; Cippitelli et al. 2015; Hansson et al. 2006). In fact, the msP rats have been proposed to phenocopy animals in a postdependent state (Ciccocioppo 2013; Ciccocioppo et al. 2006) that largely drink alcohol to self-medicate from negative effect and excessive anxiety.

NPS possesses marked anxiolytic effects in rodents; NPS treatment increased the time spent in the open arms of the EPM and the time spent in the light compartment of the light dark box, reduced marble burring behavior in mice, and enhanced the locomotor activity in the central zone of the open field (Jungling et al. 2008; Leonard et al. 2008; Meis et al. 2008; Xu et al. 2004). Therefore, we speculate that in the msP rats, the inhibition of alcohol drinking by NPS reflects the anxiolytic effect of this peptide, alleviating the anxiety of the $\mathrm{msP}$ rats and attenuating their motivation for alcohol. This hypothesis was confirmed by the results from the EPM task, showing that the msP rats spent significantly less time in the open arms of the apparatus than did the Wistar rats. This result confirmed a higher level of anxiety in the msP rats. Notably, NPS injection increased the time spent in the open arms of the EPM by the msP rats but not the Wistar rats. These rats showed that NPS specifically exerts anxiolytic effects on msP rats. A similar phenomenon was previously observed for drugs such as nociception agonists and CRF1 receptor antagonists; both classes of compounds possess marked anxiolytic effects and reduced alcohol drinking in $\mathrm{msP}$ rats but not in heterogeneous Wistar rats (Ayanwuyi et al. 2013; Ciccocioppo et al. 2014; de Guglielmo et al. 2015; Gehlert 
et al. 2007). Most importantly, our finding agrees with previous studies published in genetically selected alcoholpreferring P rats, in which ICV administration of NPS attenuated home cage alcohol drinking and elicited a marked anxiolytic effect (Badia-Elder et al. 2008). Similar to msP rats, $P$ rats are characterized by excessive alcohol drinking and elevated anxiety (Stewart et al. 1993). Our results suggest that in these alcohol-preferring rat strains, the inhibitory effect of NPS on alcohol consumption is linked to the ability of NPS to alleviate anxiety, despite the fact that NPS otherwise acts via a negative reinforcement mechanism to provide an incentive for alcohol consumption (Ciccocioppo et al. 2006; Schank et al. 2012).

Previous studies using heterogeneous Wistar rats showed that the permissive effect of NPS on cue-induced reinstatement might depend on its ability to activate the orexin/ hypocretin system, as this effect was selectively blocked by pretreatment with the hypocretin-1/orexin-A antagonist SB334867 (Cannella et al. 2009; Kallupi et al. 2010; Ubaldi et al. 2016). Moreover, the orexin/hypocretin-facilitated conditioned reinstatement of drug seeking is mediated by the direct activation of two distinct Hcrt-1/Ox-A pathways linking the lateral hypothalamus to the hypothalamic paraventricular nucleus and the bed nucleus of the stria terminalis, which are known to play a crucial role in the regulation of the stress response (Ubaldi et al. 2016). In addition to these findings, in cocaine-trained rats, ICV administration of NPS can reinstate drug-seeking behavior under extinction conditions, mimicking a priming-like mechanism (Paneda et al. 2009). This effect is prevented in animals carrying a genetic deletion of the CRF1 receptor (Paneda et al. 2009). Hence, these data provide further evidence of a tight link between the NPS system and stress regulation. We speculate that when endogenous stress systems are activated, NPS acts as a negative modulator of these systems. When they are in a minimally active state, stimulation of the orexin/hypocretin system promotes arousal and facilitates goal-oriented responses. A tempting hypothesis is that this highly evolutionarily conserved system (Reinscheid 2007) is important for preserving natural instincts in mammals by stimulating vigilance and arousal, which are necessary to survival (i.e., hunting or escaping from a predator), and for preventing excessive stimulation of stress mechanisms leading to hyperanxiety, fear, and freezing responses (Cannella et al. 2013).

In summary, our results suggest that due to its dualistic nature, NPS acts differently between msP and Wistar rats. In $\mathrm{msP}$ rats, the anxiolytic effects of NPS prevail, which results in attenuating negative emotions (i.e., reduced anxiety) and decreased incentives for alcohol. In heterogeneous Wistar rats, the pro-arousal and pro-stress properties of NPS predominate, which translates into an enhanced alcohol-seeking response in these animals. Future studies will need to determine the detailed mechanisms underlying this dualistic action of NPS, and the present study suggests that msP rats may represent an important animal model for comparison with heterogeneous rats to explore this hypothesis.

Acknowledgments We thank Rina Righi and Mariangela Fiorelli for animal care and Alfredo Fiorelli for technical support. This work was supported by National Institutes of Health grants RO1 AA017447 and RO1 AA014351 from the National Institute on Alcohol Abuse and Alcoholism

Compliance with ethical standards All procedures adhered to the European Community Council Directive and the National Institutes of Health Guidelines for the Care and Use of Laboratory Animals and were approved by the Ethics Committee of the University of Camerino (Protocol no. 1/2012)

\section{References}

Ayanwuyi LO, Carvajal F, Lerma-Cabrera JM, Domi E, Bjork K, Ubaldi M, Heilig M, Roberto M, Ciccocioppo R, Cippitelli A (2013) Role of a genetic polymorphism in the corticotropin-releasing factor receptor 1 gene in alcohol drinking and seeking behaviors of Marchigian Sardinian alcohol-preferring rats. Front Psychiatry 4:23

Badia-Elder NE, Henderson AN, Bertholomey ML, Dodge NC, Stewart RB (2008) The effects of neuropeptide $\mathrm{S}$ on ethanol drinking and other related behaviors in alcohol-preferring and -nonpreferring rats. Alcohol Clin Exp Res 32:1380-1387

Cannella N, Economidou D, Kallupi M, Stopponi S, Heilig M, Massi M, Ciccocioppo R (2009) Persistent increase of alcohol-seeking evoked by neuropeptide $\mathrm{S}$ : an effect mediated by the hypothalamic hypocretin system. Neuropsychopharmacology 34:2125-34

Cannella N, Kallupi M, Ruggeri B, Ciccocioppo R, Ubaldi M (2012) The role of the neuropeptide $\mathrm{S}$ system in addiction: Focus on its interaction with the CRF and hypocretin/orexin neurotransmission. Prog Neurobiol 100:48-59

Cannella N, Kallupi M, Ruggeri B, Ciccocioppo R, Ubaldi M (2013) The role of the neuropeptide $\mathrm{S}$ system in addiction: focus on its interaction with the CRF and hypocretin/orexin neurotransmission. Prog Neurobiol 100:48-59

Ciccocioppo R (2013) Genetically selected alcohol preferring rats to model human alcoholism. Curr Top Behav Neurosci 13:251-69

Ciccocioppo R, de Guglielmo G, Hansson AC, Ubaldi M, Kallupi M, Cruz MT, Oleata CS, Heilig M, Roberto M (2014) Restraint stress alters nociceptin/orphanin FQ and CRF systems in the rat central amygdala: significance for anxiety-like behaviors. J Neurosci 34: $\underline{363-72}$

Ciccocioppo R, Economidou D, Cippitelli A, Cucculelli M, Ubaldi M, Soverchia L, Lourdusamy A, Massi M (2006) Genetically selected Marchigian Sardinian alcohol-preferring (msP) rats: an animal model to study the neurobiology of alcoholism. Addict Biol 11:339-55

Ciccocioppo R, Panocka I, Froldi R, Colombo G, Gessa GL, Massi M (1999) Antidepressant-like effect of ethanol revealed in the forced swimming test in Sardinian alcohol-preferring rats. Psychopharmacology (Berl) 144:151-7

Cippitelli A, Ayanwuyi LO, Barbier E, Domi E, Lerma-Cabrera JM, Carvajal F, Scuppa G, Li H, Ubaldi M, Heilig M, Roberto M, Ciccocioppo R (2015) Polymorphism in the corticotropin-releasing factor receptor 1 (CRF1-R) gene plays a role in shaping the high anxious phenotype of Marchigian Sardinian alcohol-preferring (msP) rats. Psychopharmacology (Berl) 232:1083-93

de Guglielmo G, Martin-Fardon R, Teshima K, Ciccocioppo R, Weiss F (2015) MT-7716, a potent NOP receptor agonist, preferentially 
reduces ethanol seeking and reinforcement in post-dependent rats. Addict Biol 20:643-51

Gehlert DR, Cippitelli A, Thorsell A, Le AD, Hipskind PA, Hamdouchi C, Lu J, Hembre EJ, Cramer J, Song M, McKinzie D, Morin M, Ciccocioppo R, Heilig M (2007) 3-(4-chloro-2-morpholin-4-ylthiazol-5-yl)-8-(1-ethylpropyl)-2,6-dimethyl- imidazo[1,2b]pyridazine: a novel brain-penetrant, orally available corticotropin-releasing factor receptor 1 antagonist with efficacy in animal models of alcoholism. J Neurosci 27:2718-26

Ghazal P, Ciccocioppo R, Ubaldi M (2013) Morphine dependence is associated with changes in neuropeptide $\mathrm{S}$ receptor expression and function in rat brain. Peptides 46:6-12

Gozzi A, Agosta F, Massi M, Ciccocioppo R, Bifone A (2013) Reduced limbic metabolism and fronto-cortical volume in rats vulnerable to alcohol addiction. Neuroimage 69:112-9

Hansson AC, Cippitelli A, Sommer WH, Ciccocioppo R, Heilig M (2007) Region-specific down-regulation of Crhrl gene expression in alcohol-preferring msP rats following ad lib access to alcohol. Addict Biol 12:30-4

Hansson AC, Cippitelli A, Sommer WH, Fedeli A, Bjork K, Soverchia L, Terasmaa A, Massi M, Heilig M, Ciccocioppo R (2006) Variation at the rat Crhrl locus and sensitivity to relapse into alcohol seeking induced by environmental stress. Proc Natl Acad Sci U S A 103: 15236-41

Jungling K, Seidenbecher T, Sosulina L, Lesting J, Sangha S, Clark SD, Okamura N, Duangdao DM, Xu Y-L, Reinscheid RK, Pape H-C (2008) Neuropeptide S-mediated control of fear expression and extinction: role of intercalated GABAergic neurons in the amygdala. Neuron 59:298-310

Kallupi M, Cannella N, Economidou D, Ubaldi M, Ruggeri B, Weiss F, Massi M, Marugan J, Heilig M, Bonnavion P, de Lecea L, Ciccocioppo R (2010) Neuropeptide $\mathrm{S}$ facilitates cue-induced relapse to cocaine seeking through activation of the hypothalamic hypocretin system. Proc Natl Acad Sci U S A 107:19567-72

Kallupi M, de Guglielmo G, Cannella N, Li HW, Calo G, Guerrini R, Ubaldi M, Renger JJ, Uebele VN, Ciccocioppo R (2013) Hypothalamic Neuropeptide $\mathrm{S}$ receptor blockade decreases discriminative cue-induced reinstatement of cocaine seeking in the rat. Psychopharmacology (Berl) 226:347-55

Laas K, Reif A, Akkermann K, Kiive E, Domschke K, Lesch KP, Veidebaum T, Harro J (2015) Neuropeptide S receptor gene variant and environment: contribution to alcohol use disorders and alcohol consumption. Addict Biol 20:605-16

Leonard SK, Dwyer JM, Sukoff Rizzo SJ, Platt B, Logue SF, Neal SJ, Malberg JE, Beyer CE, Schechter LE, Rosenzweig-Lipson S, Ring RH (2008) Pharmacology of neuropeptide $S$ in mice: therapeutic relevance to anxiety disorders. Psychopharmacology (Berl) 197: 601-611

Leonard SK, Ring RH (2011) Immunohistochemical localization of the neuropeptide $\mathrm{S}$ receptor in the rat central nervous system. Neuroscience 172:153-63

Liu X, Zeng J, Zhou A, Theodorsson E, Fahrenkrug J, Reinscheid RK (2011) Molecular fingerprint of neuropeptide S-producing neurons in the mouse brain. J Comp Neurol 519:1847-66
Lukas M, Neumann ID (2012) Nasal application of neuropeptide S reduces anxiety and prolongs memory in rats: social versus non-social effects. Neuropharmacology 62:398-405

Meis S, Bergado-Acosta JR, Yanagawa Y, Obata K, Stork O, Munsch T (2008) Identification of a neuropeptide $\mathrm{S}$ responsive circuitry shaping amygdala activity via the endopiriform nucleus. PLoS One 3(7): e2695

Okamura N, Reinscheid RK (2007) Neuropeptide S: a novel modulator of stress and arousal. Stress 10:221-6

Paneda C, Huitron-Resendiz S, Frago LM, Chowen JA, Picetti R, de Lecea L, Roberts AJ (2009) Neuropeptide S reinstates cocaineseeking behavior and increases locomotor activity through corticotropin-releasing factor receptor 1 in mice. J Neurosci 29: 4155-4161

Pape HC, Jungling K, Seidenbecher T, Lesting J, Reinscheid RK (2010) Neuropeptide S: a transmitter system in the brain regulating fear and anxiety. Neuropharmacology 58:29-34

Paxinos G, Watson C (1988) The Rat Brain in Stereotaxic Coordinates, 4th edn. Academic Press, San Diego

Reinscheid RK (2007) Phylogenetic appearance of neuropeptide S precursor proteins in tetrapods. Peptides 28:830-7

Reinscheid RK (2008) Neuropeptide S: anatomy, pharmacology, genetics and physiological functions. Results Probl Cell Differ 46:145-58

Rizzi A, Vergura R, Marzola G, Ruzza C, Guerrini R, Salvadori S, Regoli D, Calo G (2008) Neuropeptide $S$ is a stimulatory anxiolytic agent: a behavioural study in mice. Br J Pharmacol 154:471-479

Schank JR, Ryabinin AE, Giardino WJ, Ciccocioppo R, Heilig M (2012) Stress-related neuropeptides and addictive behaviors: beyond the usual suspects. Neuron 76:192-208

Stewart RB, Gatto GJ, Lumeng L, Li TK, Murphy JM (1993) Comparison of alcohol-preferring (P) and nonpreferring (NP) rats on tests of anxiety and for the anxiolytic effects of ethanol. Alcohol 10:1-10

Ubaldi M, Giordano A, Severi I, Li H, Kallupi M, de Guglielmo G, Ruggeri B, Stopponi S, Ciccocioppo R, Cannella N (2016) Activation of hypocretin-1/orexin-A neurons projecting to the bed nucleus of the stria terminalis and paraventricular nucleus is critical for reinstatement of alcohol seeking by neuropeptide S. Biol Psychiatry 79:452-62

Vitale G, Filaferro M, Ruggieri V, Pennella S, Frigeri C, Rizzi A, Guerrini $\mathrm{R}$, Calo G (2008) Anxiolytic-like effect of neuropeptide $\mathrm{S}$ in the rat defensive burying. Peptides 29:2286-2291

Weiss F, Mitchiner M, Bloom FE, Koob GF (1990) Free-choice responding for ethanol versus water in alcohol preferring $(\mathrm{P})$ and unselected Wistar rats is differentially modified by naloxone, bromocriptine, and methysergide. Psychopharmacology (Berl) 101: $178-86$

Xu Y-L, Gall CM, Jackson VR, Civelli O, Reinscheid RK (2007) Distribution of neuropeptide S receptor mRNA and neurochemical characteristics of neuropeptide S-expressing neurons in the rat brain. J Comp Neurol 500:84-8102

Xu Y-L, Reinscheid RK, Huitron-Resendiz S, Clark SD, Wang Z, Lin SH, Brucher FA, Zeng J, Ly NK, Henriksen SJ, de Lecea L, Civelli O (2004) Neuropeptide S: a neuropeptide promoting arousal and anxiolytic-like effects. Neuron 43:487-497 